\title{
Cognitive booster of wampee peel extract on chronic restraint stress- induced memory dysfunction in rats
}

\author{
Terdthai Tongun ${ }^{1}$, Wathita Phachonpai ${ }^{*}$ \\ ${ }^{1}$ Department of Physiology, Faculty of Medicine, Khon Kaen University, Khon Kaen, Thailand, 40002. \\ ${ }^{2}$ Division of Physiology, School of Medical Sciences, University of Phayao, Phayao, Thailand, 56000.
}

\section{ARTICLE INFO \\ Received on: 05/04/2020 \\ Accepted on: 01/06/2020 \\ Available online: 04/07/2020}

\section{Key words:}

Wampee, cognitive booster, oxidative damage, stress, brain-boosting foods

\begin{abstract}
Novel antioxidants and acetylcholinesterase (AChE) inhibitors from fruits' peel could be valuable alternatives for anti-amnesia. Wampee (WP) fruits are a rich source of high antioxidants. A lack of scientific document supports the efficacy of WP peel extract to ameliorate the memory impairment against amnesia induced by chronic restraint stress (CRS) until now. This study intended to illuminate the cognitive enhancer effect of WP peel extract in a rat model of CRS. The Wistar rats were treated with the WP peel extract $(200,400$, and $600 \mathrm{mg} / \mathrm{kg})$ in a restrainer for 4 hours for 28 consecutive days. The object recognition and Morris water maze tests were used to evaluate cognitive performances. The lipid peroxidation, AChE inhibitory, and scavenging enzyme activities in the rat's brain were also investigated. CRS exposure induces oxidative stress, decreases the antioxidant enzymes but increases AChE activities, and causes memory deficit in cognitive tests. Hence, all various doses of WP peel extract were able to significantly diminish chronic stress-induced memory deficit, attenuated the brain deterioration originated by an excessive oxidative stress, and show a capacity to inhibit AChE enzyme activity. These findings indicate that WP peel extract was safe and valuable functional ingredients to develop the product for brain-boosting foods.
\end{abstract}

\section{INTRODUCTION}

Several studies have reported that chronic stress exposure has many effects on the central and peripheral nervous system and can cause deleterious effects on brain structure and cognitive function (Azman et al., 2018; Lupien et al., 2009). The reactive oxygen species (ROS) and oxidative reaction originated by prolonged stress exposure have been involved in cognitive decline (Farr et al., 2003; Li et al., 2008). Humans exposed to prolonged stress may induce the generation of free radicals and reduce the brain antioxidant enzymes activity both in the cerebral cortex and hippocampus (Moceri et al., 2000; Wang et al., 2014).

Various studies revealed that the cognitive performance in experiment animals as well as in human was correlated with the accumulation of the ACh-hydrolyzing enzyme and

"Corresponding Author

Wathita Phachonpai, Division of Physiology, School of Medical Sciences, University of Phayao, Phayao, Thailand.

E-mail:phachonpai@yahoo.com acetylcholinesterase (AChE) concentration (Croxson et al., 2011; Newman et al., 2012). Therefore, acetylcholinesterase inhibitors (AChEIs) are the current mainstays of symptomatic therapy for memory disorders (Ashford, 2015).

Nowadays, the peel of fruits or plants has gained much attention and is recommended as a rich source of fiber, minerals, vitamins, and antioxidants (Parashar et al., 2014). Researchers have studied on various fruit peels to prove that antioxidant activity exists in the peel of the fruit, such as hawthorn, banana, mango, and pomegranate peels possessing high antioxidant activities (Guo et al., 2003). However, there is limited evidence supporting the improvement of cognition through the fruits' peel consumption.

Clausena lansium (Lour.) Skeels or wampee (WP) belong to family Rutaceae that is a native plant commonly found in Northern Thailand and Southern China. It is used in China and Thai traditional medicines to prevent and treat the common cold, cough, malaria, and dermatological and digestive problems (Adebajo et al., 2009; Jackobsen et al., 1972; Stuan, 1977). It has been revealed that WP possesses the biological and pharmacological activities including antimicrobial, anti-inflammatory, antitumor, hepatoprotective, antifungal, antiobesity, antioxidant, and neuroprotective effects (Liu 
et al., 1996a, 2019b; Ng et al., 2003; Shen et al., 1989). Besides, the previous study has presented that the WP peel displays the antioxidant and anticancer properties in vitro models and SGC7901 human gastric carcinoma, HepG-2 human liver cancer cells, and A-549 human lung adenocarcinoma (Prasad et al., 2009a).

According to all the information as we mentioned above, it had led to the notion that WP peel extracts dietary consumption, which might be beneficial in combating cognitive impairment induced by chronic stress exposure (CRS). In this study, we determined whether the WP peel extract could restore the memory deficit induced by CRS through the inhibition of AChE activity or reduce the oxidative stress. The restoration of cognitive decline was gauged using the object recognition (ORT) and Morris water maze (MWM) tests. To investigate the oxidative status, the activity of endogenous antioxidant enzyme superoxide dismutase (SOD), catalase (CAT), glutathione peroxidase (GPx), and concentration of malondialdehyde (MDA) as a biomarker of lipid peroxidation in the rat brains after exposed to chronic stress was investigated.

\section{MATERIALS AND METHODS}

\section{Drug and chemicals}

Acetylthiocholine iodide (ATCI), 5,5'-dithiobis (2-nitrobenzoic acid) (DTNB), and ATCI were purchased from Tokyo Chemicals Industry (Tokyo, Japan). Thiobarbituric acid (TBA), 2,4-dinitrophenylhydrazine, and Vitamin C were purchased from Sigma Chemical Co. (St. Louis, MO). All other chemicals and reagents with analytical grade and were purchased from Merck (Darmstadt, Germany).

\section{Preparation of the crude extract}

The ripe fruits of WP were collected from Amphoe Tanao, Nan Province, Thailand, and were processed directly after it obtained at the laboratory. WP's peels were removed and washed carefully with tap water and dried with hot air oven at $40^{\circ} \mathrm{C}$. The dried materials were homogenized and macerated in a mixture of ethanol and distilled water for 48 hours. The WP peel extract was filtered and concentrated by a rotary evaporator. The percentage yield of the final extract was $10.93 \%$ and stored at $4^{\circ} \mathrm{C}$ in lightprotected flasks until studied further in the animals.

\section{Animals}

Adult male Wistar rats weighing 200-250 g from Nomura Siam International Co. Ltd., Bangkok, Thailand, were used in this study. The experimental protocols were approved by the Institutional Animal Care and Committee of the University of Phayao, Thailand (No. 620104024) and followed the principles of Laboratory Animal Care (National Institutes of Health publication, \#85-23, revised in 1985).

All rats were housed in standard metal cages under control at ambient temperature of $22^{\circ} \mathrm{C} \pm 2{ }^{\circ} \mathrm{C}$ with a relative humidity of $55 \% \pm 10$ and 12:12-hours light-dark cycle. They were fed with commercial pellet diet and clean water ad libitum. The animals were permitted to adjust to the new environment for 7 days before the experiment was started.

\section{Experimental protocol}

After acclimatization, 40 rats were divided into different groups ( $n=8$ /group) as follows:
Group I: Vehicle + CRS; rats had been treated with vehicle (distilled water)

Group II: Vitamin C + CRS; rats had been treated with Vitamin C (100 mg/kg; a standard antioxidant and attenuate memory impairment)

Group III-V: WP peel + CRS; rats had been treated with WP peel extract $(200,400$, and $600 \mathrm{mg} / \mathrm{kg})$, all doses of the extracts were chosen based on the doses of WP peel extract which showed the memory-enhancing effect from the preliminary data.

All substances were given via oral gavage at 7:00 a.m. once a day for 28 days. For chronic stress induction, all rats were started to expose the immobilization stress for 4 hours' daily, approximately 30 minutes after oral administration.

\section{Chronic restraint stress (CRS) method}

All animals were exposed to CRS daily between 8:00 and 12:00 a.m. for 28 consecutive days. The restraint stress was accomplished using a plastic tube $\left(20 \times 7 \mathrm{~cm}^{2}\right.$ in diameter $)$. There was $3-\mathrm{mm}$ hole at the end of the tube for breathing, and the other side of the tube was closed with a plexiglass lid. The rat was permitted ample air but unable to move, and food or water was deprived.

At the end of the study, both spatial and nonspatial memory performances were determined by the ORT and MWM tests, respectively. Rats were anesthetized with ether and decapitated immediately after the cognition assessment.

Whole rat's brain was rapidly removed, washed with isotonic ice-cold $\mathrm{NaCl}$ solution, and weighed and homogenized in sodium phosphate buffer $\mathrm{pH} 7.4$ with Triton X-100 using PotterElvehjem homogenizer under ice-cold condition at $4^{\circ} \mathrm{C}$. After centrifugation at $9,000 \mathrm{~g}, 4^{\circ} \mathrm{C}$ for 30 minutes, the supernatants were stored at $-70^{\circ} \mathrm{C}$ for measured $\mathrm{AChE}$ activity, SOD and CAT activities, and MDA concentration.

\section{Object recognition (ORT) test}

The apparatus consisted of a plexiglass $(70 \times 50 \times 40$ $\mathrm{cm})$ and a metal triangular $(7 \times 5 \times 10 \mathrm{~cm})$ and rectangular plastic $(5 \times 5 \times 10 \mathrm{~cm})$ were used as objects to be separated. On day 1 , the rats were permitted to explore the test apparatus without objects for 180 seconds. Two identical objects were then presented after 24 hours for exploration (T1). Object exploration was assessed when the rat sniffed or touched the object $<2 \mathrm{~cm}$ from its nose and was allowed to explore both objects freely for 5 minutes, and then, the rat was moved back into the cage. The ORT apparatus was cleaned with $10 \%$ ethanol solution and tissue paper to eliminate any remaining odor impregnation.

Retrieval memory was verified 24 hours' later, in which one of the objects was replaced by a novel one. Rats were allowed to explore a novel and familiar object for 5 minutes. The time spent on exploring each object was recorded by a stopwatch. The results were shown as the discrimination index (DI), which is defined as the explorative time for the new object and the familiar object during the retention test.

\section{Morris water maze (MWM) test}

The learning and memory function of rats were assessed by MWM test (Morris, 1994). A circular water tank $(170 \mathrm{~cm}$ in diameter and $60 \mathrm{~cm}$ in height) was filled with powder water at a temperature of $22^{\circ} \mathrm{C} \pm 2{ }^{\circ} \mathrm{C}$ (depth $40 \mathrm{~cm}$ ). The pool was divided into four quadrants. A platform (10 cm in diameter) was hidden for 2 
$\mathrm{cm}$ under the surface of the powder water on a fixed location in one of the four quadrants. The platform remained in the same location throughout the study. All rats were given four trials per day, each trial having a time of 60 seconds and a trial interval of 30 seconds. The escape latency represented the time until the rat reached the underwater target platform. To determine the retention memory, it was investigated on the next day. The platform moved out of the pool, and the rat allowed to swim to find the hidden platform for 60 seconds. The time spent to find the platform in the target quadrant called the retention time, which indicated that the degree of memory consolidation taken place after learning. Cognitive abilities would be reflected by a shorter escape latency and a longer retention time.

\section{AChE activity determination}

Rat's brain AChE inhibition activity was measured by Ellman's colorimetric procedure (Ellman et al., 1961). Briefly, in the 96-well plates, $25 \mu \mathrm{l}$ of $15 \mathrm{mM}$ ATCI, $75 \mu \mathrm{l}$ of $3 \mathrm{mM}$ DTNB, and $75 \mu \mathrm{l}$ of $50 \mathrm{mM}$ Tris $-\mathrm{HCl}$ at $\mathrm{pH} 8.0$ were added to the supernatant obtained from $20 \% \mathrm{w} / \mathrm{v}$ brain homogenate $(10 \mu \mathrm{l})$. The blank solution was prepared similarly for all the test samples but used the phosphate buffer instead of ATCI, and the absorbance was monitored spectrophotometrically by a microplate reader at $412 \mathrm{~nm}$ for 3 minutes at regular intervals of 30 seconds.

\section{Lipid peroxidation determination}

MDA is an index of lipid peroxidation, which was estimated by the Okhawa et al. (1979) method. Briefly, the reagents of $1.5 \mathrm{ml} 20 \%$ of acetic acid, $0.2 \mathrm{ml} 8.1 \%$ of sodium dodecyl sulfate, and $1.5 \mathrm{ml} 0.8 \%$ of TBA was added to $0.1 \mathrm{ml}$ brain tissue sample. The mixture was heated at $100^{\circ} \mathrm{C}$ for 60 minutes and then cooled with tap water; $1.0 \mathrm{ml}$ of distilled water, 5 $\mathrm{ml}$ of $\mathrm{n}$-butanol, and pyridine were added and centrifuged at 4,000 rpm for 10 minutes. Supernatants were carefully aspirated, and the pink chromogen was measured at $532 \mathrm{~nm}$ by a spectrophotometer (Shimadzu Corporation, Kyoto, Japan).

\section{SOD activity determination}

SOD activity was accessed by the method of Kakkar et al. (1984). The reaction mixture of SOD activity contained $1.2 \mathrm{ml}$ of sodium pyrophosphate buffer $(0.052 \mathrm{mM}, \mathrm{pH} 8.0), 0.1$ $\mathrm{ml}$ of phenazine methosulphate $(186 \mu \mathrm{M})$, nitroblue tetrazolium $(300 \mu \mathrm{M})$, and $0.3 \mathrm{ml}$ of brain supernatant and incubated at $37^{\circ} \mathrm{C}$ for 5 minutes before adding $0.2 \mathrm{ml}$ of $\mathrm{NADH}(780 \mu \mathrm{M})$. The mixture solution was incubated for 2 minutes at $37^{\circ} \mathrm{C}$, and 1.0 $\mathrm{ml}$ of glacial acetic acid $(17.4 \mathrm{M})$ was added to stop the reaction. The absorbance of the colored product was measured at $560 \mathrm{~nm}$ against reagent blank and was expressed as units/mg protein.

\section{Catalase activity determination}

The activity of CAT enzyme was determined by the method of Aebi (1984) with minor modifications. Briefly, the reaction mixture solution contained $2.5 \mathrm{ml}$ of $50 \mathrm{mM}$ phosphate buffer (pH 7.0), $0.4 \mathrm{ml}$ of $5.9 \mathrm{mM} \mathrm{H} 2 \mathrm{O} 2$, and $0.1 \mathrm{ml}$ of enzyme extract. CAT activity was recorded a decrease in absorbance at 240 $\mathrm{nm}$ of a reaction mixture and was expressed as units/mg protein.

\section{Glutathione peroxidase (GSH-Px) activity determination}

GSH-Px was carried out by the method of Paglia and Valentine (1967). Briefly, the reaction mixture of GSH-Px containing $0.1 \mathrm{ml}$ of GSH $(0.15 \mathrm{M}), 0.3 \mathrm{ml}$ of sodium phosphate buffer (0.1 M, pH 7.4), $0.05 \mathrm{ml}$ of sodium azide $(2.25 \mathrm{M}), 0.2 \mathrm{ml}$ of NADPH $(0.85 \mathrm{mM}), 0.05 \mathrm{ml}$ of brain homogenate, and $0.05 \mathrm{ml}$ of glutathione reductase $(2 \mathrm{U} / \mathrm{ml})$ was vortexed and incubated for 10 minutes at room temperature. The reaction of GSH-Px activity was started by the addition of $0.05 \mathrm{ml}$ of $\mathrm{H}_{2} \mathrm{O}_{2}(0.0011 \mathrm{M})$. The absorbance was verified at $340 \mathrm{~nm}$ for 3 minutes. Results were reported as units/mg protein.

\section{Statistical analysis}

The statistical evaluation was accomplished with Statistical Package for the Social Sciences version 11 software. All results were analyzed using one-way analysis of variance followed by post hoc Tukey's test and expressed as mean \pm SEM. A level of $p<0.05$ was considered to be statistically significant.

\section{RESULTS}

\section{Cognitive booster effects of WP peel extract on spatial and nonspatial memory}

No toxic effects or unexpected mortality were observed in all rats treated with WP extract at various doses ranging from 200,400 , and $600 \mathrm{mg} / \mathrm{kg}$, which indicate that the crude extract of WP peel was considered to be safe at the dosing schedule used.

The cognitive booster effect of WP peel extract in the ORT is shown in Figure 1. The result showed that pretreatment with three doses of WP peel extract and Vitamin C increased the DI exploration time as compared to the vehicle plus CRS group $(p<0.05$ all $)$.

In MWM test, escape latencies in all doses of WP peel extract plus CRS rats were significantly $(p<0.05)$ lower than in the vehicle plus CRS group. The escape latency in the Vitamin C plus CRS group was also significantly $(p<0.05)$ lower than those of the vehicle plus CRS group. Moreover, WP peel extract at various dose levels could also increase in retention time $(p<0.05$ all) as compared to vehicle plus CRS group. A similar induction of the retention time to that found in Vitamin C group (Fig. 2).

Taking these results together suggested that chronic stress exposure leads to impaired both in spatial and nonspatial memories. However, the oral administration of WP peel extract was effective in preventing and enhancing memory under the conditions of chronic stress exposure.

\section{Effects of WP extract on brain oxidation indices and antioxidant enzymes}

As shown in Figure 3, the significant decrease in SOD, CAT, and GSH-Px activities was observed in rat brains of the vehicle plus CRS group. However, all of the antioxidant enzyme activities as mention earlier were significantly $(p<0.05$ all) restored in three different doses of WP peel extract plus CRS groups compared with that in the vehicle plus CRS group. Similarly, the SOD, CAT, and GSH-Px activities in rat brains of 


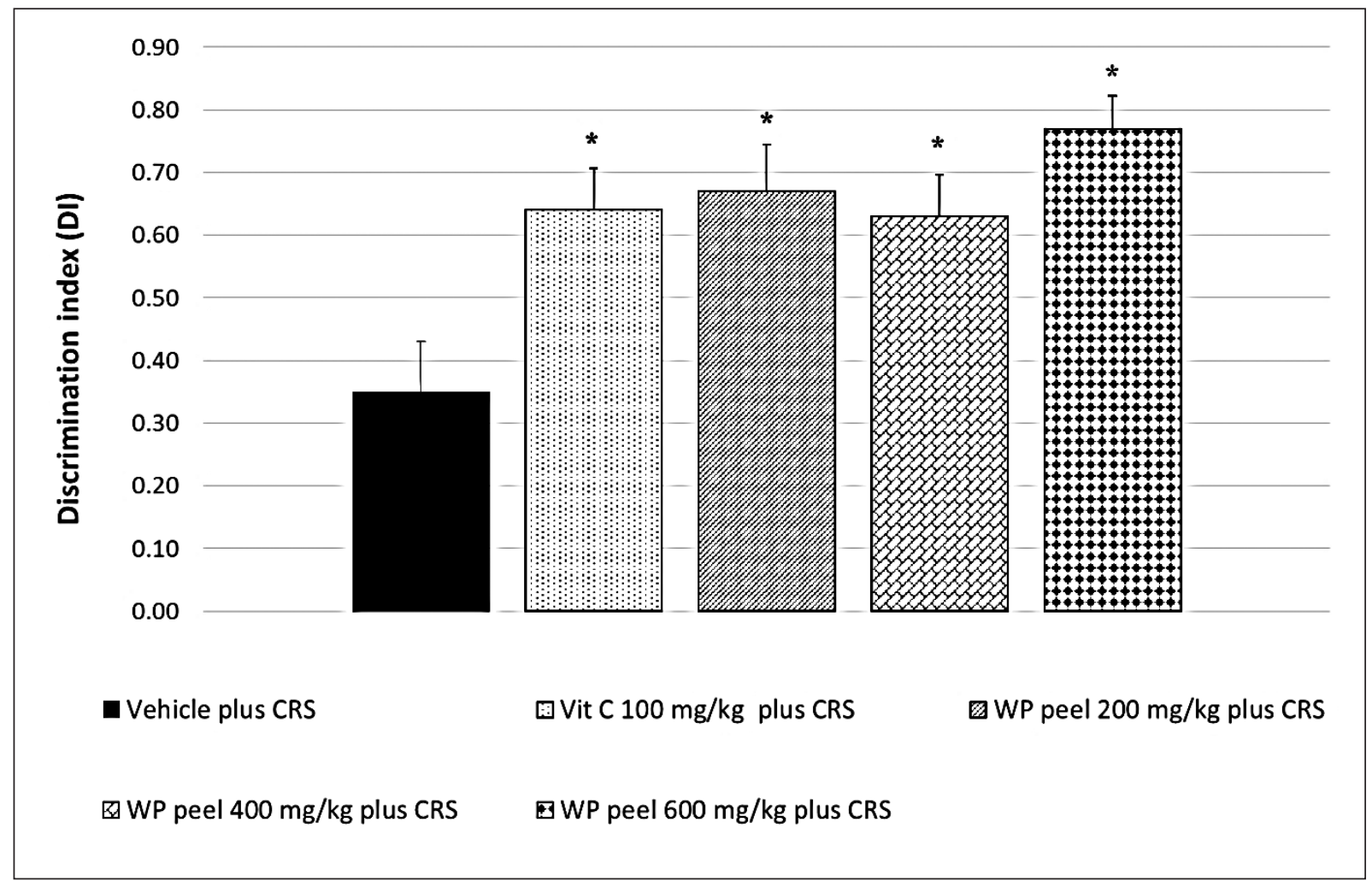

Figure 1. Effects of WP peel extract orally for 28 days on the DI in the ORT in chronic restraint stressed rats. Values represent the mean \pm SEM $(n$ $=8) .{ }^{*} p<0.05$ as compared to vehicle plus CRS group.

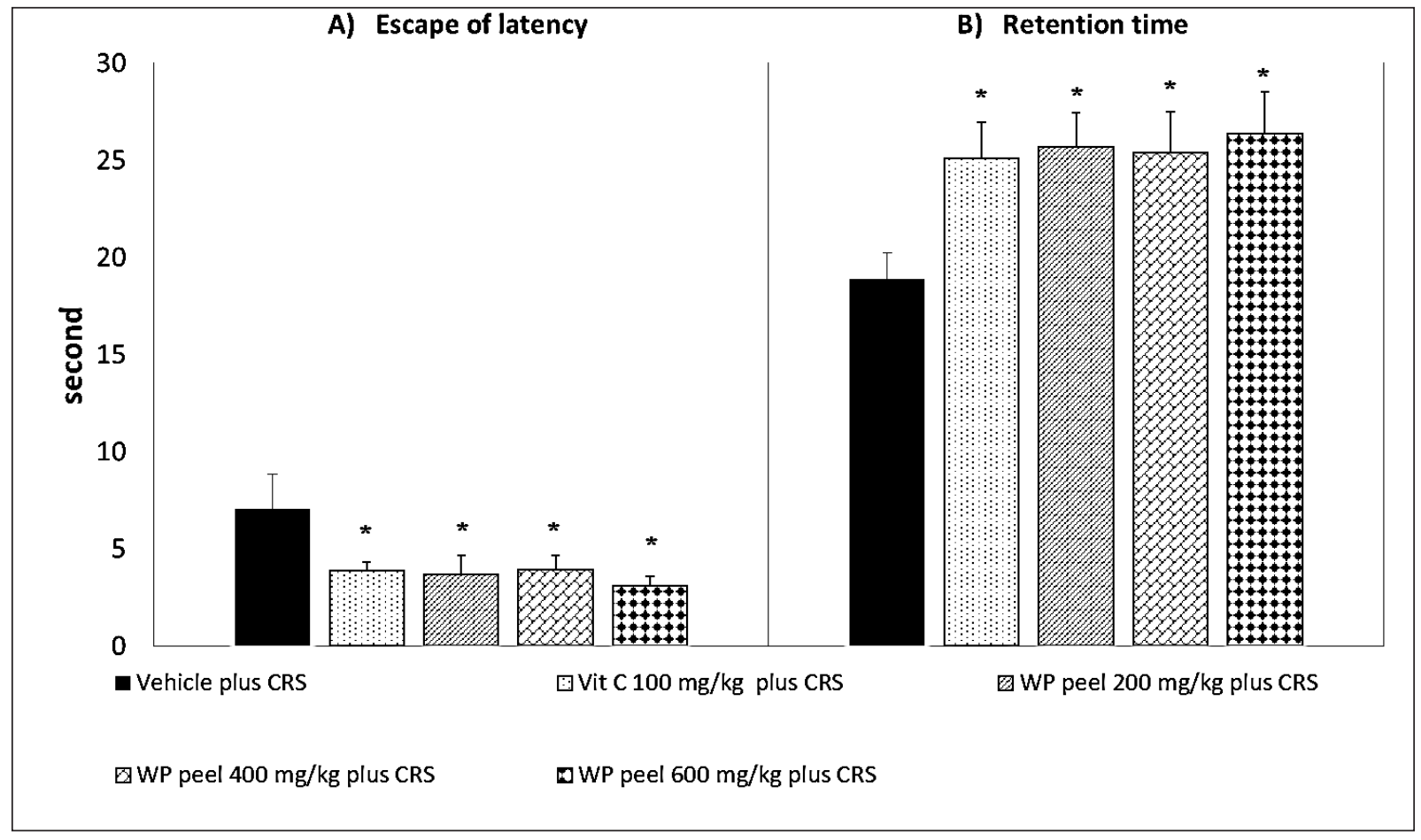

Figure 2. Effects of WP peel extract orally for 28 days on the escape latency and retention time in the MWM test in chronic restraint stressed rats. Values represent the mean $\pm \operatorname{SEM}(n=8) .{ }^{*} p<0.05$ as compared to vehicle plus CRS group. 


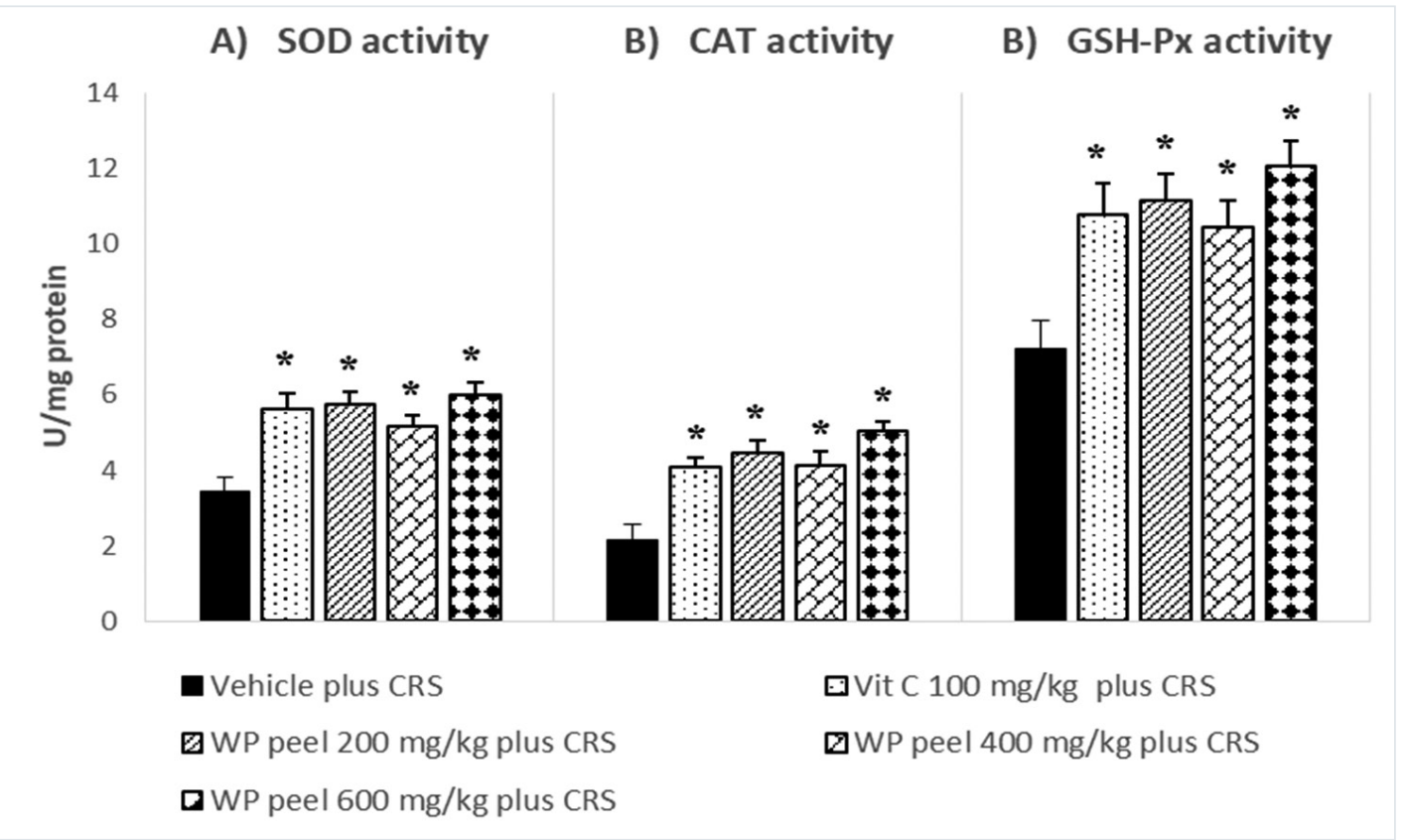

Figure 3. Effects of WP peel extract orally for 28 days on SOD, CAT, and GSH-Px of the brain in chronic restraint stressed rats. Values represent the mean $\pm \operatorname{SEM}(n=8) .{ }^{*} p<0.05$ as compared to vehicle plus CRS group.

the Vitamin C plus CRS was significantly $(p<0.05)$ increased compared with that in the vehicle plus CRS group.

The depletion of brain scavenging enzymes activity is linked with the lipid peroxidation level in the brain. The result showed that the MDA level in the rat brain of the vehicle plus CRS group was higher than in other groups. Again, the pretreatment with three different doses of WP peel extract used in this study reversed the changes of this phenomenon ( $p<0.05$ all), indicating the ability of this fruit peel extract to restore the brain antioxidant enzyme activity and reduce lipid peroxidation caused by chronic stress exposure (Fig. 4).

\section{Anti-AChE activity of WP peel extract}

Abundant evidence indicate that cognitive performance is related with the cholinergic system including the AChE activity (Ballinger et al., 2016; Bohnen et al., 2018). The result showed that all various doses of WP peel extract were able to cause a significant $(p<0.05)$ decrease in the AChE activity (Fig. 5). It should be noted here that the pretreatment with Vitamin $\mathrm{C}$ to restraint stress rats for 28 days had no anti-AChE activity.

\section{DISCUSSION}

Based on the recent reports that have been revealed, the fruits' peel of some fruits rich in antioxidant potency may prevent or reduce the severity of many diseases (Al-Sayed and Ahmed, 2013; Larrosa et al., 2002). This study shows that the extract of WP peel has the potential to be utilized as one of the products to alleviate memory impairments due to chronic stress exposure in a rat model.

It has long been accepted that cognitive decline is affected by exposure to chronic stress (Moench et al., 2019). CRS-induced memory impairment is an outcome of different mechanisms, such as activation of the hypothalamic-pituitary-adrenal (HPA) axis and alteration in the central neurotransmitters contents, increases the production of ROS, and induces brain oxidative damage (Liu et al., 1996c; Seckl et al., 1993). According to these results, which are in agreement with the previous documents, CRS leads to neurophysiopathological dysfunctions characterized by progressive memory deficits manifested via cognitive process impairment as well as changes in several biochemical indices (McEwen, 2004; Ohl and Fuchs, 1999). The results showed that the exposure to CRS for 28 days caused a significant increase in brain MDA level and decrease in the endogenous antioxidant enzymes such as SOD, CAT, and GPx and led to a significant cognitive deficit which was obvious through the significantly higher mean escape latency but lower retention time in MWM test. Besides, CRS exposure decreased the DI in the ORT which indicated that CRS model approaches are suitable to determine the cognitive booster effects of WP peel extract in amnesia management caused by chronic stress exposure.

To identify the cognitive booster effects of WP peel extract on spatial and nonspatial memories, the MWM and ORT, respectively, were used. In the ORT, oral administration with all doses of WP peel extract significantly increased the DI scores to a novel objects. Besides, three doses of this extract produced a significant decrease in escape latency and an increase in retention time in the MWM test. These results indicate that WP peel extract enhanced memory performances and ameliorated the cognitive decline involved with chronic stress exposure. The previous study suggested that the retention time score of the MWM test is considered to reflect retrieval memory ability (Vorhees and Williams, 2014), which indicates that WP peel extract consumption ameliorated long-term memory impairment significantly in rats following exposure to chronic stress. 


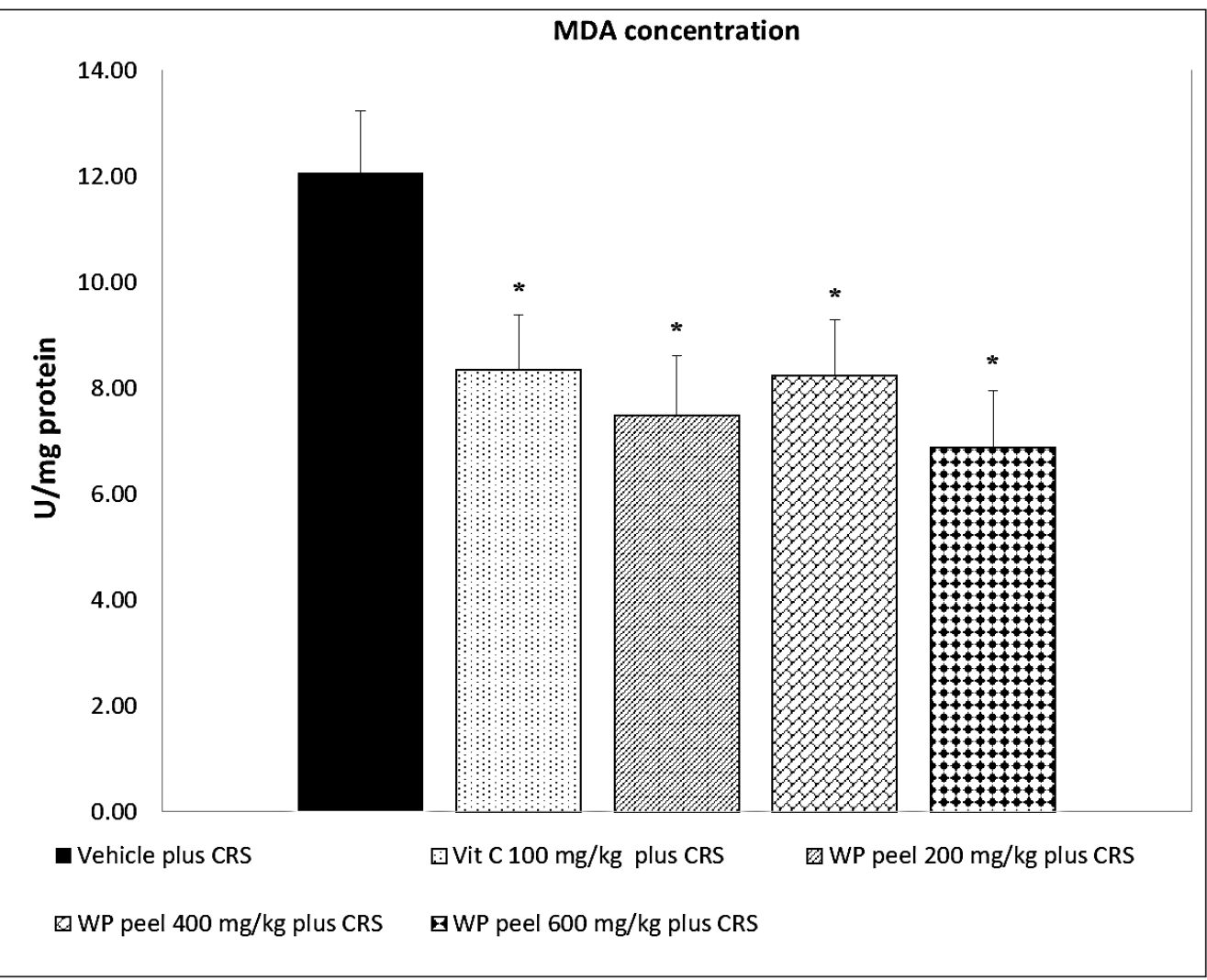

Figure 4. Effects of WP peel extract orally for 28 days on MDA of the brain in chronic restraint stressed rats. Values represent the mean $\pm \operatorname{SEM}(n=8) .{ }^{*} p<0.05$ as compared to vehicle plus CRS group.

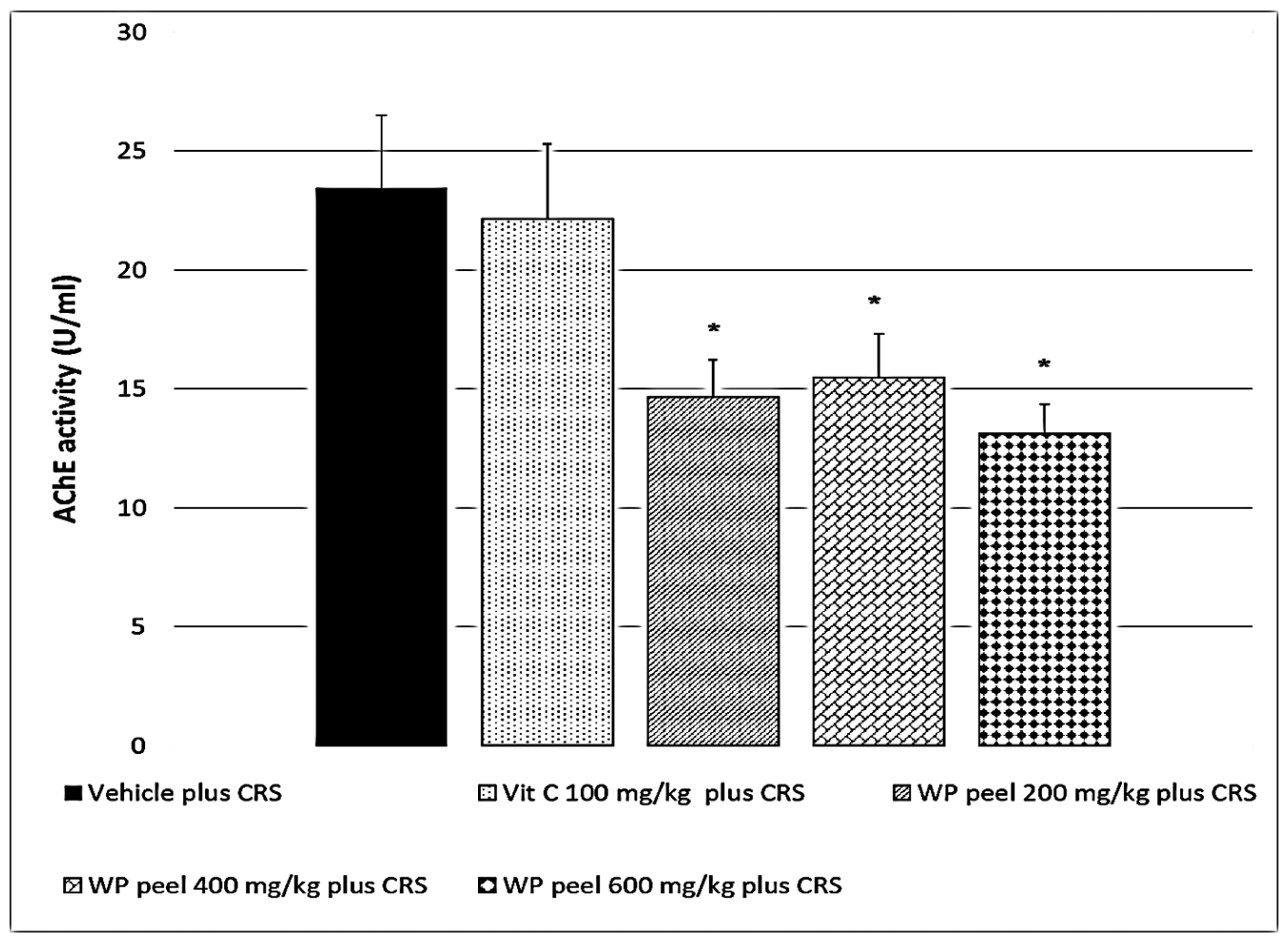

Figure 5. Effects of WP peel extract orally for 28 days on brain AChE activity in chronic restraint stressed rats. Values represent the mean $\pm \operatorname{SEM}(n=8) .{ }^{*} p<0.05$ as compared to vehicle plus CRS group. 
Concerning the accumulation of data on the vital role of oxidative stress in the development of cognitive disorders, it is suggested to use antioxidant compounds as a novel strategy to protect against cognitive disorders (Bhattacharya et al., 2001). Besides, many researchers initially focused on developing the health-promoting products from the waste of fruits, which exerts antioxidant effects (Cheok et al., 2018).

Multiple lines of evidence report the role of acetylcholine (ACh), which was a neurotransmitter responsible for the memory and cognition (Hampel et al., 2018; Schliebs and Arendt, 2011). According to the "cholinergic hypothesis," AChE is a key enzyme responsible for the degradation of ACh. Therefore, the strategy to block the AChE activity for maintaining ACh level is necessary for treating amnesia.

To identify the possible mechanisms of WP peel extract on cognitive improvement, the current results reveal that WP peel extract consumption significantly restored the reduced activities of brain scavenging enzymes, SOD, CAT, GPx, and decreased MDA level, induced by CRS that led to cognitive impairment. These findings are in accordance with the previous studies that reported that WP peel extract possessed high phenolic contents and presented a strong antioxidant activity in vitro (Prasad et al., 2009b). Besides, WP peel extract administration reversed the increase of AChE activity in the rat brain, which indicates that WP peel extract acts as AChEIs. Thus, the cognitive booster effects of WP peel extract on memory deficit of CRS rats may be related to its antioxidant and $\mathrm{AChE}$ inhibitory activities. However, the role of WP peel extract in CRS-induced memory deficit on HPA axis activity still remains to be clarified.

WP peel extract at a dose of $600 \mathrm{mg} / \mathrm{kg}$ revealed a better efficacy than other doses. However, its effect is not in a dose-dependent manner, suggesting that the WP peel extract used in this study was the crude extract and contained multiple bioactive compounds. Therefore, the antioxidant and the cognitive booster effects of WP peel extract may occur via the synergistic effects of several bioactive compounds in these crude extracts. The identification of active compounds from WP peel extract responsible for a given cognitive enhancing effect is necessary.

\section{CONCLUSION}

The nutshell of our study can be concluded that WP peel extract attenuates memory distortion and oxidative stress and acts as AChI in rats exposed to CRS. The results of this study indicate that WP peel extract consumption was safe, and its therapeutic potential is used to develop the product for brain-boosting foods. Nevertheless, further studies are necessary to identify the major bioactive compounds and the exact mechanisms of cognitive enhancing effect of WP peel extract.

\section{ACKNOWLEDGMENT}

All authors are grateful to Associate Professor Dr. Jintanaporn Wattanathorn, Department of Physiology, Faculty of Medicine, Khon Kaen University, for her permission to use the facilities of the laboratory.

Authors' contributions: WP: designed \& conducted all laboratory experiments, prepared manuscript. TT: participated in the study and performed the statistical analysis.

\section{CONFLICT OF INTEREST}

There was no conflict of interests in this study. All authors declare that we do not have any commercial or associative interest that represents a conflict of interest in connection with the work submitted.

\section{FUNDING}

The authors sincerely acknowledge the University of Phayao, Thailand (grant number of R020058217044), provided financial support for this study.

\section{REFERENCES}

Adebajo AC, Iwalewa EO, Obuotor EM, Ibikunle GF, Omisore NO, Adewunmi CO, Obaparusi OO, Klaes M, Adetogun GE, Schmidt TJ, Verspohl EJ. Pharmacological properties of the extract and some isolated compounds of Clausena lansium stem bark: anti-trichomonal, antidiabetic, anti-inflammatory, hepatoprotective and antioxidant effects. J Ethnopharmacol, 2009; 122:10-9.

Aebi H. Catalase in vitro. In: Colowick SP, Kaplan NO (eds.) Methods in enzymology. Acad. Press, Orlando, FL, 105, pp 114-21, 1984.

Al-Sayed HMA, Ahmed AR. Utilization of watermelon rinds and sharlyn melon peels as a natural source of dietary fiber and antioxidants in cake. Annals of Agri Sci, 2013; 58:83-95.

Ashford JW. Treatment of Alzheimer's disease: the legacy of the cholinergic hypothesis, neuroplasticity, and future directions. J Alzheimers Dis, 2015; 47:149-56.

Azman KF, Zakaria R, Othman Z, Abdul Aziz CB. Neuroprotective effects of tualang honey against oxidative stress and memory decline in young and aged rats exposed to noise stress. J Taibah Univ Sci, 2018; 12:273-84.

Ballinger EC, Ananth M, Talmage DA, Role LW. Basal forebrain cholinergic circuits and signaling in cognition and cognitive decline. Neuron, 2016; 91:1199-218.

Bhattacharya A, Ghosal S, Bhattacharya S. Anti-oxidant effect of Withania somnifera glycolwithanolides in chronic foot shock stressinduced perturbations of oxidative free radical scavenging enzymes and lipid peroxidation in rat frontal cortex and striatum. J Ethnopharmacol, 2001; 74:1-6.

Bohnen NI, Grothe MJ, Ray NJ, Müller MLTM, Teipel SJ. Recent advances in cholinergic imaging and cognitive decline-Revisiting the cholinergic hypothesis of dementia. Curr Geriatr Rep, 2018; 7:1-11.

Cheok CY, Mohd Adzahan N, Abdul Rahman R, Zainal Abedin $\mathrm{NH}$, Hussain N, Sulaiman R, Chong GH. Current trends of tropical fruit waste utilization. Crit Rev Food Sci Nutr, 2018; 58:335-61.

Croxson PL, Kyriazis DA, Baxter MG. Cholinergic modulation of a specific memory function of prefrontal cortex. Nat Neurosci, 2011; $14: 1510-2$.

Ellman GL, Courtney KD, Andres V, Featherstone RM. A new and rapid colorimetric determination of acetylcholinesterase activity. Biochem Pharmacol, 1961; 7:88-95.

Farr SA, Poon HF, Dogrukola-Ak D, Drake J, Banks WA, Eyerman E, Butterfield DA, Morley JE. The antioxidants alpha-lipoic acid and $\mathrm{N}$-acetylcysteine reverse memory impairment and brain oxidative stress in aged SAMP8 mice. J Neurochem, 2003; 84:1173-83.

Guo CY, Wei J, Li Y, Xu J, Jiang Y. Antioxidant activities of peel, pulp and seed fractions of common fruits as determined by FRAP assay. Nutr Res, 2003; 23:1719-26.

Hampel H, Mesulam MM, Cuello AC, Farlow MR, Giacobini E, Grossberg GT, Khachaturian AS, Vergallo A, Cavedo E, Snyder PJ, Khachaturian ZS. The cholinergic system in the pathophysiology and treatment of Alzheimer's disease. Brain, 2018; 141:1917-33.

Jackobsen HB, Friis P, Kan WS. Mannual of medicinal plants in Taiwan. National Research Institute of Chinese Medicine Press 2, Taipei, Taiwan, p 372, 1972. 
Kakkar PS, Das B, Viswanathan PN. A modified spectrophotometric assay of superoxide dismutase. Ind J Biochem Biophys, 1984; 21:130-2.

Larrosa M, Llorach R, Espın JC, Tomás-Barberán FA. Increase of antioxidant activity of tomato juice upon functionalisation with vegetable byproduct extracts. LWT - Food Sci Tech, 2002; 35:532-42.

Li S, Wang C, Wang W, Dong H, Hou P, Tang Y. Chronic mild stress impairs cognition in mice: from brain homeostasis to behavior. Life Sci, 2008; 82:934-42.

Liu GT, Li WX, Chen YY, Wei HL. Hepatoprotective action of nine constituents isolated from the leaves of Clausena lansium in mice. Drug Dev Res, 1996a; 39:174-8.

Liu J, Wang X, Shigenaga M, Yeo H, Mori A, Ames B. Immobilization stress causes oxidative damage to lipid, protein, and DNA in the brain of rats. FASEB J, 1996b; 10:1532-8.

Liu YP, Guo JM, Liu YY, Hu S, Yan G, Qiang L, Fu YH Carbazole Alkaloids with potential neuroprotective activities from the fruits of Clausena lansium. J Agric Food Chem, 2019c; 67:5764-71.

Lupien SJ, McEwen BS, Gunnar MR, Heim C. Effects of stress throughout the lifespan on the brain, behaviour and cognition. Nat Rev Neurosci, 2009; 10:434-45.

McEwen BS. Protection and damage from acute and chronic stress: allostasis and allostatic overload and relevance to the pathophysiology of psychiatric disorders. Ann N Y Acad Sci, 2004; 1032:1-7.

Moceri VM, Kukull WA, Emanuel I, van Belle G, Larson EB. Early-life risk factors and the development of Alzheimer's disease. Neurology, 2000; 54:415-20.

Moench KM, Breach MR, Wellman CL. Chronic stress produces enduring sex- and region-specific alterations in novel stress-induced c-Fos expression. Neurobiol Stress, 2019; 10:100147.

Morris RG. Working memory in Alzheimer-type dementia. Neuropsychology, 1994; 8:544-54.

Newman EL, Gupta K, Climer JR, Monaghan CK, Hasselmo ME. Cholinergic modulation of cognitive processing: insights drawn from computational models. Front Behav Neurosci, 2012; 6:24.

Ng TB, Lam SK, Fong WP. A homodimeric sporamin-type trypsin inhibitor with antiproliferative, HIV reverse transcriptase-inhibitory and antifungal activities from wampee (Clausena lansium) seeds. Biol Chem, 2003; 384:289-93.

Ohl F, Fuchs E. Differential effects of chronic stress on memory processes in the tree shrew. Brain Res Cogn Brain Res, 1999; 7:379-87.

Okhawa H, Ohishi N, Yagi K. Assay of lipid peroxides in animals tissue by thiobarbituraic acid reaction. Anal Biochem, 1979; 95:351-8.
Paglia DE, Valentine WN. Studies on quantitative and qualitative characterization of erythrocyte glutathione peroxidase. J Lab Clin Med, 1967; 70:158-69.

Parashar S, Sharma H, Garg M. Antimicrobial and Antioxidant activities of fruits and vegetable peels: a review. J Pharmacogn Phytochem, 2014; 3:160-4.

Prasad KN, Hao J, Yi C, Zhang D, Qiu S, Jiang Y, Zhang M, Chen F. Antioxidant and anticancer activities of wampee (Clausena lansium (Lour.) Skeels) peel. J Biomed Biotechnol, 2009a; 2009:612805.

Prasad NK, Yang B, Ruenroengklin N, Zhao M, Jiang Y. Application of ultrasonication or high pressure to assist extraction of flavonoids from litchi fruit pericarp. J Food Process Eng, 2009b; 32:828-43.

Schliebs R, Arendt T. The cholinergic system in aging and neuronal degeneration. Behav Brain Res, 2011; 221:555-63.

Seckl JR, French KL, O’Donnell D, Meaney MJ, Nair N, Yates CM, Fink G. Glucocorticoid receptor gene expression is unaltered in hippocampal neurons in Alzheimer's disease. Brain Res Mol Brain Res, $1993 ; 18: 239-45$

Shen ZF, Chen QM, Liu HF, Xie MZ. The hypoglycemic e-ect of clausenacoumarine. Yao Xue Xue Bao, 1989; 24:391-2.

Stuan G. Manual on some Philippine medicinal plants. U.P. Botanical Society, Philippines, 1977.

Vorhees CV, Williams MT. Assessing spatial learning and memory in rodents. ILAR J, 2014; 55:310-32.

Wang Y, Kan H, Yin Y, Wu W, Hu W, Wang M, Li W, Li W. Protective effects of ginsenoside Rg1 on CRS induced learning and memory impairments in male mice. Pharmacol Biochem Behav, 2014; 120:73-81.

How to cite this article:

Tongun T, Phachonpai W. Cognitive booster of wampee peel extract on chronic restraint stress-induced memory dysfunction in rats. J Appl Pharm Sci, 2020; 10(07):019-026. 